\title{
Programmed cell death in Leishmania: biochemical evidence and role in parasite infectivity
}

\section{Sreenivas Gannavaram and Alain Debrabant*}

Laboratory of Emerging Pathogens, Division of Emerging and Transfusion Transmitted Diseases, Center for Biologics Evaluation and Research, Food and Drug Administration, Bethesda, MD, USA

Edited by:

Stephen M. Beverley, Washington

University in St. Louis, USA

\section{Reviewed by:}

Dario S. Zamboni, Universidade de São Paulo, Brazil

Vincent J. Starai, The University of Georgia, USA

\section{*Correspondence:}

Alain Debrabant, Laboratory of Emerging Pathogens, Division of

Emerging and Transfusion

Transmitted Diseases, Center for Biologics Evaluation and Research, Food and Drug Administration, 29,

Lincoln Drive, B29, Rm425,

HFM-310, Bethesda, MD 20892,

USA.

e-mail: alain.debrabant@fda.hhs.gov
Demonstration of features of a programmed cell death (PCD) pathway in protozoan parasites initiated a great deal of interest and debate in the field of molecular parasitology. Several of the markers typical of mammalian apoptosis have been shown in Leishmania which suggested the existence of an apoptosis like death in these organisms. However, studies to elucidate the downstream events associated with phosphotidyl serine exposure, loss of mitochondrial membrane potential, cytochrome c release, and caspase-like activities in cells undergoing such cell death remain an ongoing challenge. Recent advances in genome sequencing, chemical biology should help to solve some of these challenges. Leishmania genetic mutants that lack putative regulators/effectors of PCD pathway should not only help to demonstrate the mechanisms of PCD but also provide tools to better understand the putative role for this pathway in population control and in the establishment of a successful infection of the host.

Keywords: apoptosis, endonuclease, Leishmania, metacaspase, programmed cell death, protozoa, trypanosomatid

\section{INTRODUCTION}

Programmed cell death (PCD), commonly manifested as apoptosis, plays crucial roles in a multitude of physiological processes starting from embryogenesis to maintenance of the immune system. Evolutionarily, apoptosis emerged along with multicellular organisms, primarily as a host defense mechanism against viral infections (Ameisen, 1996). However, since the first description of a PCD-like pathway in trypanosomatid parasites (Ameisen et al., 1995), increasing experimental evidence has accumulated suggesting that similar processes also appear to exist in many single-celled parasitic organisms including Plasmodium species (Al-Olayan et al., 2002; Ch'ng et al., 2010), Toxoplasma gondii (Peng et al., 2003), Trichomonas vaginalis (Chose et al., 2002), Entamoeba histolytica (Villalba et al., 2007), and Giardia lamblia (Ghosh et al., 2009). In trypanosomatids, features suggesting PCD have been reported in response to a wide range of stimuli such as heat shock, reactive oxygen species, antiparasitic drugs, prostaglandins, and antimicrobial peptides (Lee et al., 2002; Duszenko et al., 2006; Jimenez-Ruiz et al., 2010). Many biochemical events that accompany mammalian apoptosis such as generation of reactive oxygen species, increase in cytosolic $\mathrm{Ca}^{2+}$ levels, alterations in mitochondrial outer membrane potential, exposure of phosphatidylserine (PS) in the outer leaflet of the plasma membrane, release of cytochrome $\mathrm{c}$, activation of caspaselike activities and nucleases that cleave genomic DNA have also been widely documented in trypanosomatid parasites (Sereno et al., 2001; Arnoult et al., 2002; Lee et al., 2002; Mukherjee et al., 2002; Zangger et al., 2002; Debrabant et al., 2003; van Zandbergen et al., 2010). Although autophagy-related processes typically used by cells as a survival mechanism in response to stress have also been shown to lead to cell death under certain conditions (Debnath et al., 2005), their contribution to PCD in parasitic protozoan remains to be elucidated. Therefore, this review will only focus on the evidence for a PCD pathway in Leishmania and review the putative molecules involved in such pathway, if adequately demonstrated. We discuss the putative role of $\mathrm{PCD}$ in Leishmania infectivity and suggest future approaches to better understand the role of such cell death pathway in Leishmania and related trypanosomatid parasites.

\section{BIOCHEMICAL EVIDENCE OF PROGRAMMED CELL DEATH IN Leishmania MORPHOLOGICAL CHANGES}

In metazoan organisms, cell morphology during execution phase of apoptosis is accompanied by characteristic changes that are distinct from other forms of cell death namely autophagy and necrosis (Klionsky et al., 2008; Kroemer et al., 2009; Galluzzi et al., 2012). Loss of cell volume with an intact plasma membrane is considered a hallmark of a cell undergoing apoptotic death unlike necrotic death where such loss of volume is usually a result of non-intact plasma membrane (Kroemer et al., 2009; Galluzzi et al., 2012). Leishmania parasites go through a series of distinct morphological shapes and sizes during their life cycle in the insect vector and mammalian hosts. These distinct developmental stages during the normal differentiation of the parasite have been well-characterized (Handman, 1999; Gossage et al., 2003). During its differentiation from procyclic to metacyclic promastigotes in the sand fly vector, the body of the parasite undergoes dramatic 
shrinkage which is associated with autophagic processes (Besteiro et al., 2006) that do not culminate in cell death. However, the morphological changes observed during Leishmania PCD (e.g., cell shrinkage, nuclear condensation) are not well understood; therefore, unlike for metazoans, cell shrinkage cannot be used as a reliable marker of PCD in these organisms.

\section{PHOSPHATIDYLSERINE EXPOSURE AT THE CELL SURFACE}

Phospholipid composition in the plasma membrane of mammalian cells is not identical between the two leaflets of the membrane bilayer. The outer leaflet is predominantly composed of choline-containing phospholipids, phosphatidylcholine, and sphingomyelin, whereas the aminophospholipids, phosphatidylethanolamine, and PS populate the inner leaflet (Bevers and Williamson, 2010). This asymmetry in the lipid composition is maintained in quiescent cells by an ATP-dependent mechanism (Tang et al., 1996). However, in apoptotic cells such asymmetry is lost and as a result PS is exposed at the cell surface that can be detected by its reactivity with annexin-V (Martin et al., 1995). This PS exposure was identified as an early event in cells undergoing apoptosis regardless of the stimuli in mammalian apoptosis. Several studies in Leishmania reported PS exposure in stationary phase promastigotes and also in response to heat shock, serum deprivation, and a range of chemical inducers based on annexin$\mathrm{V}$ binding to these parasites which is widely used maker of PCD in these organisms (de Freitas Balanco et al., 2001; Jimenez-Ruiz et al., 2010). Moreover, PS-dependent recognition and engulfment of Leishmania parasites by mammalian phagocytic host cells have been proposed as a mechanism for invading macrophages and in inducing an anti-inflammatory response by macrophages and dendritic cells (Wanderley et al., 2006). Recently, exposure of PS on L. amazonensis parasites derived from skin lesions has been shown to correlate with diffuse cutaneous leishmaniasis compared to localized lesions (França-Costa et al., 2012). Similar PS exposure-dependent mechanism is also utilized by vaccinia virus to enter host cells (Mercer and Helenius, 2008). In mammalian cells, membrane bound protein(s) are considered essential for exposure of PS as a result of collapsed asymmetry in lipid distribution and the protein likely responsible for this membrane scrambling activity was identified as phospholipid scramblase 1 (Bevers and Williamson, 2010). However, Leishmania and other trypanosomatid parasite genomes do not have an easily identifiable sequence homolog of this protein, underlining the importance of further studies to assess the mechanism of PS exposure to the cell surface of Leishmania. In addition, annexin- $\mathrm{V}$ is also known to bind anionic phospholipids other than PS. Reagents that could specifically react with PS such as PS-specific monoclonal antibodies or molecular pattern recognition reagents such as aptamers may be of value in confirming that PS is indeed expressed on the cell surface of Leishmania.

\section{CYTOCHROME C RELEASE}

In mammalian cells, two major signaling cascades lead to apoptosis. The extrinsic cascade is mediated by activation of tumor necrosis family receptors, also known as death receptors. In contrast, the intrinsic cell death pathway is triggered by stimuli such as cytokine deprivation, DNA damage, and cytotoxic stress and is orchestrated by mitochondria (Brenner and Mak, 2009). The pro-apoptotic Bcl-2 members Bax, Bak, Bid, and others initiate the mitochondrial cell death pathway by permeabilizing the mitochondrial outer membrane. This allows the release of proapoptotic factors from the mitochondria such as cytochrome $c$, which binds to the adaptor protein Apaf-1 resulting in the activation of caspase-9 (Brenner and Mak, 2009; Pradelli et al., 2010; Abdelwahid et al., 2011; Huttemann et al., 2011). In addition, mitochondrial alterations including disruption of electron transport, oxidative phosphorylation and ATP production, release of other proteins such as Htr2/Omi, Smac/Diablo that trigger caspase activation and changes of cellular redox potential also contribute to the intrinsic PCD pathway (Green and Reed, 1998; Pradelli et al., 2010). Release of cytochrome c has been well documented in many species of Leishmania in response to several apoptotic stimuli (Gannavaram et al., 2008; Jimenez-Ruiz et al., 2010). This was also observed when the proapoptotic mammalian Bax protein was exogenously expressed in Trypanosoma brucei (Esseiva et al., 2004). However, release of cytochrome c in isolation may be of limited utility as a definite marker of Leishmania PCD unless downstream events are better understood. This is because even though cytochrome $\mathrm{c}$ is released from the inter membrane space of mitochondria into the cytoplasmic compartment of Leishmania, no evidence for downstream events such as binding to Apaf- 1 and activation of caspase9 homologs has been demonstrated. Homology searches in the Leishmania genome databases indicate the presence of a possible homologue of Apaf-1 protein (Table 1). It would be interesting to investigate if this protein indeed has Apaf- 1 activity (i.e., bind to Leishmania cytochrome $\mathrm{c}$ and promote cell death). Mouse genetic studies have shown that Lys72 of cytochrome $\mathrm{c}$ is essential for its interaction with Apaf-1, and a mutant lacking the Lys72 can still function in electron transport chain (Hao et al., 2005). However, in a knock-in mouse with this mutation even though Apaf-1 oligomerization did not occur, caspase activation indeed took place suggesting that Apaf-1 may only speed up apoptosis but is not absolutely required for apoptosis to proceed further (Ekert et al., 2004). On the other hand, in yeast, cytochrome c release from mitochondria has been suggested to promote cell death although causal explanation is lacking (Ludovico et al., 2002). These reports suggest that similar to yeast, the release of cytochrome $\mathrm{c}$ in Leishmania needs further investigation in order to identify the signaling events associated with this molecule that are involved in PCD. This would help to define further a putative intrinsic PCD pathway in Leishmania.

\section{CASPASE-LIKE AND METACASPASE ACTIVITIES}

Caspases and the members of the Bcl-2 family are the most important regulators of the apoptotic process in metazoans. In protozoan parasites, however, there is very little information about the existence of homologs of the Bcl-2 proteins, even though some indirect evidence indicates that $\mathrm{Bcl} 2$-responsive proteins may exist in Leishmania (Alzate et al., 2006). On the other hand, extensive evidence for the existence of caspase-like activities associated with parasite PCD has been published (Lee et al., 2002; Paris et al., 2004; Sen et al., 2004; Singh et al., 2005). These groups have reported the activation of proteases 
Table 1 | We searched the literature and conducted BLASTP homology searches, followed by reciprocal best-hit analysis, to assemble a list of Leishmania homologs of the putative regulators or effectors of PCD.

\begin{tabular}{|c|c|c|c|c|}
\hline $\begin{array}{l}\text { Human homolog } \\
\text { (UniProt) }\end{array}$ & $\begin{array}{l}\text { BLASTP reciprocal } \\
\text { best-hit }\end{array}$ & High-score & Expectation value & Reference(s) \\
\hline $\begin{array}{l}\text { Endonuclease G } \\
\text { (Q14249) }\end{array}$ & $\begin{array}{l}\text { LmjF.10.0610 } \\
\text { LinJ.10.0660 }\end{array}$ & $\begin{array}{l}150 \\
147\end{array}$ & $\begin{array}{l}4.1 e-22 \\
3.0 e-21\end{array}$ & $\begin{array}{l}\text { Gannavaram et al., } 2008 \\
\text { BoseDasgupta et al., } 2008 \\
\text { Rico et al., } 2009\end{array}$ \\
\hline $\begin{array}{l}\text { TatD deoxyribonuclease } \\
\text { (Q6P1N9) }\end{array}$ & $\begin{array}{l}\text { LmjF.11.1280 } \\
\text { LinJ.11.1270 }\end{array}$ & $\begin{array}{l}599 \\
593\end{array}$ & $\begin{array}{l}2.2 e-59 \\
9.6 e-59\end{array}$ & $\begin{array}{l}\text { Gannavaram and Debrabant, } \\
2012 \\
\text { BoseDasgupta et al., } 2008\end{array}$ \\
\hline $\begin{array}{l}\text { Flap endonuclease } 1 \\
\text { (FEN1) (P39748) }\end{array}$ & $\begin{array}{l}\text { LmjF.27.0250 } \\
\text { LinJ.27.0260 }\end{array}$ & $\begin{array}{l}909 \\
905\end{array}$ & $\begin{array}{l}1.6 e-92 \\
4.2 e-92\end{array}$ & BoseDasgupta et al., 2008 \\
\hline $\begin{array}{l}\text { Apoptosis-inducing factor } 1 \\
\text { (AIF1) (O95831) }\end{array}$ & $\begin{array}{l}\text { LmjF.32.3310 } \\
\text { LinJ.32.3510 }\end{array}$ & $\begin{array}{l}111 \\
114\end{array}$ & $\begin{array}{l}0.00049 \\
0.00023\end{array}$ & none \\
\hline $\begin{array}{l}\text { Apoptotic } \\
\text { protease-activating factor } 1 \\
(\mathrm{O} 14727)\end{array}$ & $\begin{array}{l}\text { LmjF.10.0780 } \\
\text { LinJ.10.0830 }\end{array}$ & $\begin{array}{l}299 \\
303\end{array}$ & $\begin{array}{l}2.2 e-25 \\
5.1 e-26\end{array}$ & none \\
\hline
\end{tabular}

We identified homologs for five of such regulators or effectors of PCD. Some of these molecules have been characterized in terms of their biochemical activities and role in PCD but others need future studies. We did not identify homologs for any of the other mitochondrial or other organelles based molecules with roles in metazoan apoptosis (http://stke.sciencemag.org/cgi/cm/stkecm;CMP_18019; Bergmann and Steller, 2010).

able to degrade classical substrates of mammalian caspases in Leishmania undergoing PCD. Even though caspase-like activities have been repeatedly reported these protease activities do not appear to be due to bona fide caspases, due to the fact that "caspase" genes have not been found in any of the available complete Leishmania genomes and none of the genes encoding the caspase-like enzymatic activities reported in Leishmania have been cloned.

Orthologs of caspases, i.e., metacaspases (MCs) and paracaspases, have been identified first from slime mold and later from several plants (Uren et al., 2000). MCs are cysteine proteases with structural similarity to caspases containing a catalytic cysteine histidine dyad. However, biochemical analyses revealed that MCs have distinct substrate specificity (Lys/Arg) from caspases (Asp). A role for MCs in PCD has been reported in plants, yeasts, and protozoan parasites including Leishmania (Silva et al., 2005; Lee et al., 2007; Meslin et al., 2007; Coll et al., 2010). Most Leishmania species contain a single MC gene except in $L$. infantum and L. donovani subtypes where two MCgenes have been found (Lee et al., 2007). Structurally, Leishmania MCs contain a central active domain containing the conserved catalytic cysteine and histidine dyad and a proline-rich C-terminal domain (Lee et al., 2007). In L. donovani, LdMC1 and LdMC2 cleave arginine/lysine containing substrates without any requirement for proteolytic activation, neither in normal conditions nor upon oxidative stress-induced PCD. LdMCs were reported to be stored in acidocalcisomes and released from these vesicles when cells were treated with hydrogen peroxide (Lee et al., 2007). Further, Leishmania overexpressing LdMC1 were more sensitive to hydrogen peroxide treatment suggesting a role in PCD (Lee et al., 2007). In contrast to LdMCs, the L. major MC (LmjMC) was reported to be activated by autoprocessing and its recombinant putative catalytic domain was $\sim 300$ times more active than the full-length recombinant enzyme for cleaving a fluorogenic substrate containing GGR residues in vitro (Gonzalez et al., 2007). LmjMC overexpression was found to enhance $L$. major sensitivity to oxidative stress as measured by the increase of phosphotidyl serine exposure at the parasites surface and the rapid loss of mitochondrial membrane potential, also suggesting a role in Leishmania PCD (Gonzalez et al., 2007; Zalila et al., 2011). However, the physiological substrates of Leishmania MCs remain to be identified. Interestingly, similar to Leishmania, Plasmodium MC has also been shown to exhibit a calcium-dependent, arginine-specific protease activity. Further expression of $P$. falciparum metacsapse in the yeast MC null mutant increased its susceptibility to undergo cell death under oxidative stress (Meslin et al., 2011). A promising approach that could yield valuable information regarding proteins that are substrates for MCs is the activity based probes that have been successfully employed in characterizing several cysteine proteases (Bogyo et al., 2000), kinases (Cohen et al., 2005), and phosphatases (Kumar et al., 2004). Identification of cellular substrates is the first step in further elucidating the role of MC in Leishmania PCD. A non-apoptotic role has also been ascribed to LmjMC. LmjMC was found to play a role during organelle segregation and cell-cycle progression under normal physiological conditions (Ambit et al., 2008). In addition, LmjMC null mutants were only viable when LmjMC was re-expressed from an episome at physiological levels, thus reinforcing its importance in parasite survival (Ambit et al., 2008). These observations suggest that Leishmania MCs could have separate roles depending on the environmental conditions. Additional studies will be needed to better understand the various roles of MCs in Leishmania.

\section{NUCLEASE ACTIVITIES}

Among the putative effector molecules of Leishmania PCD, nucleases have been best characterized. Since no bona fide caspase 
has been detected in trypanosomatid parasite, caspase-dependent DNase is unlikely to be encoded by their genomes as evidenced by the absence of any homolog of caspase-activated DNase (CAD) in their genomes. In mammalian apoptosis, two endonucleases are known to be involved in DNA fragmentations that do not require activation by caspases. These are apoptosis inducing factor (AIF) and endonuclease G (EndoG). EndoG has been shown to be a mitochondrial enzyme that is released in response to inducers of apoptosis and is involved in DNA degradation of dying cells (Li et al., 2001). In Leishmania, EndoG-mediated DNA degradation has been independently demonstrated in three different laboratories using hydrogen peroxide or pharmacological agents (BoseDasgupta et al., 2008; Gannavaram et al., 2008; Rico et al., 2009). The overexpression of EndoG in Leishmania resulted in spontaneous DNA fragmentation in amastigotes and not in the promastigotes, suggesting that additional factors necessary for efficient DNA degradation are expressed in a stage-specific manner (Gannavaram et al., 2008). In L. major, oxidative stress associated with the differentiation process induced high levels of PCD when EndoG is overexpressed in L. major parasites (Gannavaram et al., 2008). Also, induction of oxidative burst in macrophages by LPS and IFN- $\gamma$ treatment triggered PCD in intracellular amastigotes compared to non-stimulated host cells indicating that oxidative burst can induce PCD even in wild type parasites. These results suggested a role for EndoG in Leishmania PCD.

Functional genomic studies in C. elegans showed that several nucleases are involved in DNA degradation observed during apoptosis (Parrish and Xue, 2003). They include nuc-1, cps-6, AIF, cell death-related nucleases 1-6, and cyclophilin-13 (Parrish et al., 2001; Wang et al., 2002; Parrish and Xue, 2003). In Leishmania, indirect evidence is presented for a role of additional nucleases such as TatD-related nuclease and flap endonuclease in DNA degradation during PCD (BoseDasgupta et al., 2008). Recently, we described the involvement of TatD nuclease during PCD in the protozoan parasite Trypanosoma brucei. T. brucei TatD nuclease showed intrinsic DNase activity was localized in the cytoplasm and translocated to the nucleus where it could interact with EndoG when cells were treated with inducers that cause PCD. Over-expression of TatD nuclease resulted in elevated PCD and conversely, loss of TatD expression by RNAi conferred significant resistance to the induction of PCD in T. brucei (Gannavaram and Debrabant, 2012). These results show that T. brucei overexpressing TatD spontaneously undergo PCD under conditions that the parasites are likely to encounter in a human host, supporting a role of TatD in PCD in trypanosomatid parasites.

An AIF homolog has been shown to be translocated from the mitochondria to the nucleus after the onset of PCD in Dictyostelium discoideum (Arnoult et al., 2001). Recent searches in the Leishmania genomes suggested the presence of a weak homolog of AIF (Table 1). It would be of interest to investigate if this molecule has nuclease activity associated with PCD. Additionally, a recent report demonstrated in C. elegans the role of DICER in mediating DNA strand breaks during cell death associated with the normal development of this organism (Nakagawa et al., 2010). DICER usually degrades double stranded RNA into small RNAs that are involved in gene silencing. The unusual change in substrate specificity of DICER from a dsRNA to a DNA is accompanied by proteolytic cleavage of its carboxy terminal region (Nakagawa et al., 2010). In comparison to other eukaryotic cells, most Leishmania species are known to have lost the machinery required for dsRNA-mediated RNA interference except $L$. braziliensis and other species within the Leishmania subgenus Viannia (Lye et al., 2010). It would be of interest to investigate if L. braziliensis DICER has DNase activity that is pertinent to PCD. In addition, since DICER activity has also been demonstrated in T. brucei (Shi et al., 2006), the putative role of this molecule in T. brucei PCD could be an interesting avenue to pursue.

\section{ROLE OF Leishmania PCD IN PARASITE INFECTIVITY AND SURVIVAL POPULATION CONTROL}

Several arguments have been made recently about the existence of a PCD pathway and the physiological functions that such pathway might serve in the life cycle of unicellular parasites. For instance, PCD is considered useful in regulating the parasite cell density in the host as a mean of avoiding hyperparasitism. In Plasmodium, a PCD-like mechanism was suggested as a modality for limiting parasite density in the mosquito and in the mammalian hosts (Al-Olayan et al., 2002; Deponte and Becker, 2004). T. brucei parasites have been hypothesized to utilize PCD to regulate their cell densities in the insect vector and in mammalian host in response to the changing host antibody repertoire because of the variations in antigenic composition on its surface (Welburn and Maudlin, 1997; Vassella et al., 1997). Further, it has been shown that addition of prostaglandin D2 to cultures inhibited growth of bloodstream form parasites and induced an apoptosislike cell death (Figarella et al., 2005). These observations led to the hypothesis that the high serum prostaglandin levels in the mammalian host may play a role in regulating parasite densities by inducing cell death (Figarella et al., 2005; Duszenko et al., 2006). However, definitive evidence that links the role of PCD in controlling parasite density in either mammalian or invertebrate hosts for Plasmodium or T. brucei is lacking. Similar evidence demonstrating a role for PCD in the regulation of parasite population is also lacking in Leishmania even though apoptotic features have been widely demonstrated in these parasites (Luder et al., 2010). To that end, the development of genetic mutants lacking the putative regulators/effectors of Leishmania PCD described so far (e.g., MC or EndoG null mutants) would be extremely useful to evaluate the role of parasite PCD in maintaining host-parasite equilibrium.

\section{MODULATION OF HOST IMMUNITY}

PCD has also been considered to influence the outcome of an infection during the early phase of interactions between parasites and their mammalian host. Recently it has been proposed that for establishing a successful L. major infection in mice, the presence of apoptotic parasites in the inoculum was a key determinant (van Zandbergen et al., 2006, 2010). This was based on the observation that presence of annexin- $\mathrm{V}$ binding parasites within the inoculum leads to increased uptake by neutrophils that are attracted to the site of infection before the macrophages 
home in van Zandbergen et al. (2004, 2006). This was accompanied by the release of anti-inflammatory cytokines such as TGF- $\beta$, IL-10 and lipids such as lipoxinA4 and down-regulation of pro-inflammatory cytokines such as TNF- $\alpha$ and lipids like leukotriene-B4, which could favor parasite survival. In addition, in the L. major infection, when the annexin- $\mathrm{V}$ binding parasites were depleted from the inoculum, the presumably non-apoptotic parasites had limited virulence as indicated by the reduced size of the lesions. Further, the release of the anti-inflammatory cytokine TGF- $\beta$ by the neutrophils correlated with the dose of the annexin- $\mathrm{V}$ binding parasites in the inoculum. Also there was an inverse correlation between the annexin- $\mathrm{V}$ binding parasites and the secretion of pro-inflammatory cytokine TNF- $\alpha$. (van Zandbergen et al., 2006). These observations led to the hypothesis that the "eat-me" signal represented by the annexin-V binding on the parasites surface promotes immunologically "silent" uptake of the Leishmania parasites by macrophages and dendritic cells, as was observed in other immunosuppressive effects of apoptotic cells in mammalian homeostatic cell death (Huynh et al., 2002; van Zandbergen et al., 2006; Obeid et al., 2007). For this silent uptake to happen, the parasites in the inoculum must be able to recruit phagocytic cells to the inoculation site since the phagocytes require chemotactic guidance. There is some evidence to indicate that neutrophils are recruited by a Leishmania chemotactic factor and this activity is likely present in the lipid fraction of the parasites (van Zandbergen et al., 2007). Additional chemotactic signals such as lysophosphatidylcholine, sphingosine 1-phosphate and CX3CL1/fractalkine have been described for their potential to recruit professional phagocytes such as macrophages ( $\mathrm{Li}, 2012)$. However, roles of such additional "find me" signals in the context of a Leishmania infection remain to be investigated. In a Leishmania infection, neutrophils migrate to the site within $40 \mathrm{~min}$ and localize around bite sites (Peters et al., 2008). The neutrophils recognize the phosphotidyl serine exposed on a subpopulation in the metacyclics and phagocytose the cells in the inoculum in a non-immunogenic mechanism.

Recently, calreticulin, mostly know as an endoplasmic reticulum (ER) chaperone protein, was shown to also function as "eat me" signals (Obeid et al., 2007). Calreticulin was shown to be upregulated on the surface of apoptotic cancer cells that favored their uptake by phagocytic cells in a non-immunogenic "silent" mechanism (Obeid et al., 2007; Martins et al., 2010). The role of calreticulin as an ER chaperone molecule has been previously characterized in Leishmania (Debrabant et al., 2002). Whether this protein is also exposed at the surface of Leishmania to facilitate their silent entry into the host phagocytic cells needs to be investigated. Additionally, mannose binding lectins or lung surfactant proteins $\mathrm{A}$ and $\mathrm{D}$ have also been shown to act as eat-me signals (Ogden et al., 2001; Vandivier et al., 2002). In contrast, negative regulators of phagocytosis such as lactoferrin have also been described (Bournazou et al., 2009). All this diversity of signals indicates that phagocytosis is a finely regulated process with broad physiological effects and in principle parasites might utilize many signals to gain silent entry into a host cell. Therefore, it would be pertinent to explore such signaling pathways that promote non-immunogenic uptake of Leishmania.

\section{FUTURE PERSPECTIVES}

Analysis of genetic mutants facilitated robust demonstration of the existence of genetically PCD pathways in multicellular organisms and retention of those pathways in multicellular organisms is clearly understood from an evolutionary stand point. However, the selection of a PCD pathway in unicellular organisms such as Leishmania is less clear and remains to be explained from an evolutionary point of view. Studies in yeast suggested arguments in support of a PCD pathway in single cell organisms. For instance, in co-culture experiments, yeast persistently infected with dsRNA viruses were shown to induce PCD in uninfected yeast cells (Ivanovska and Hardwick, 2005; Schmitt and Reiter, 2008). PCD did not occur in a yeast mutant lacking MC, demonstrating the existence of this conserved cell death pathway in a single cell organism. Recently, Leishmania parasites infected with a dsRNA virus have been shown to cause metastatic spreading of the otherwise localized cutaneous lesions (Ives et al., 2011). This metastasis involved modulation of host immunity by viral RNA that resulted in heightened host pro-inflammatory responses (Ronet et al., 2011). Studies in virally infected Leishmania parasites analogous to those in yeast might help clarify the existence of a PCD pathway in Leishmania parasites and support its selection in single cell organisms.

In comparison to C. elegans and yeast, studies elucidating molecular mechanisms of PCD in trypanosomatid parasites are limited primarily because of the apparent absence of homologues to key regulatory or effector molecules of apoptosis in the trypanosomatid genomes that have been described in mammalian or nematode apoptosis such as Bcl-2 family members and caspases (Smirlis et al., 2010). Searches in annotated Leishmania genomes reveal that homology based searches offer limited clues in attempts to deciphering the mechanisms mediating PCD machinery in these parasites (Table 1). The absence of homologues of key regulatory or effector molecules of mammalian apoptosis in trypanosomatid parasites suggests that their PCD pathways are probably less evolved than apoptotic pathways of mammalian cells. Although still poorly understood, the existence of conserved PCD pathways in trypanosomatid parasites can provide targets for developing novel chemotherapies. Recent pharmacological studies elicited interest in several molecules with activities that trigger apoptotic death in cancerous cells as potential antiparasitic agents (Fuertes et al., 2008).

Studies with genetic mutants that lack regulators/effectors of PCD (e.g., MC or EndoG null mutants) would clarify the role of each of these proteins in Leishmania PCD. However, this approach is contingent upon the fact that analysis of such mutants can yield evidence for a role in PCD under appropriate settings, as the same molecule may have multiple functions in the cell including functions unrelated to PCD. For instance, EndoG null mutant mice have been shown to be associated with impaired mitochondrial respiration and increased production of reactive oxygen species, indicating that pro-apoptotic activities of this nuclease are likely to be specialized functions for this protein (David et al., 2006; McDermott-Roe et al., 2011). Similarly, studies using Leishmania genetic mutants lacking regulators/effectors of PCD may help better understand the role of this pathway in the survival of 
the parasite population in its invertebrate host. For example, to determine if PCD of non-metacyclic Leishmania parasites occurs in an infected sand fly and contributes to the survival of infectious metacyclic forms which is the only stage that is transmitted and can establish a successful infection in the mammalian host and therefore ensure the propagation of the species.

In summary, our knowledge of Leishmania PCD is still very fragmented. In the last ten years, several putative effector molecules of such pathway have been identified and characterized to various degrees. Similar effector molecules have also been shown to be involved in PCD pathways in other protozoan parasites suggesting that a common pathway might be conserved among this group of organisms. So far molecules regulating this pathway are unknown. In Leishmania the mitochondria appears to play a central role in this pathway (e.g., release of cytochrome $\mathrm{c}$ and proapoptotic nucleases) and therefore displays similarities

\section{REFERENCES}

Abdelwahid, E., Rolland, S., Teng, X., Conradt, B., Hardwick, J. M., and White, K. (2011). Mitochondrial involvement in cell death of nonmammalian eukaryotes. Biochim. Biophys. Acta 1813, 597-607.

Al-Olayan, E. M., Williams, G. T., and Hurd, H. (2002). Apoptosis in the malaria protozoan, Plasmodium berghei: a possible mechanism for limiting intensity of infection in the mosquito. Int. J. Parasitol. 32, 1133-1143.

Alzate, J. F., Alvarez-Barrientos, A., Gonzalez, V. M., and JimenezRuiz, A. (2006). Heat-induced programmed cell death in Leishmania infantum is reverted by $\mathrm{Bcl}-\mathrm{X}(\mathrm{L})$ expression. Apoptosis 11, 161-171.

Ambit, A., Fasel, N., Coombs, G. H., and Mottram, J. C. (2008). An essential role for the Leishmania major metacaspase in cell cycle progression. Cell Death Differ. 15, 113-122.

Ameisen, J. C. (1996). The origin of programmed cell death. Science 272, 1278-1279.

Ameisen, J. C., Idziorek, T., BillautMulot, O., Loyens, M., Tissier, J. P., Potentier, A., and Ouaissi, A. (1995). Apoptosis in a unicellular eukaryote (Trypanosoma cruzi): implications for the evolutionary origin and role of programmed cell death in the control of cell proliferation, differentiation and survival. Cell Death Differ. 2, 285-300.

Arnoult, D., Akarid, K., Grodet, A., Petit, P. X., Estaquier, J., and Ameisen, J. C. (2002). On the evolution of programmed cell death: apoptosis of the unicellular eukaryote Leishmania major involves cysteine proteinase activation and mitochondrion permeabilization. Cell Death Differ. 9, 65-81.

Arnoult, D., Tatischeff, I., Estaquier, J., Girard, M., Sureau, F., Tissier, J. P., Grodet, A., Dellinger, M., Traincard, F., Kahn, A., Ameisen, J. C., and Petit, P. X. (2001). On the evolutionary conservation of the cell death pathway: mitochondrial release of an apoptosis-inducing factor during Dictyostelium discoideum cell death. Mol. Biol. Cell 12, 3016-3030.

Bergmann, A., and Steller, H. (2010). Apoptosis, stem cells, and tissue regeneration. Sci. Signal. 3, re8.

Besteiro, S., Williams, R. A., Morrison, L. S., Coombs, G. H., and Mottram, J. C. (2006). Endosome sorting and autophagy are essential for differentiation and virulence of Leishmania major. J. Biol. Chem. 281, 11384-11396.

Bevers, E. M., and Williamson, P. L. (2010). Phospholipid scramblase: an update. FEBS Lett. 584, 2724-2730.

Bogyo, M., Verhelst, S., BellingardDubouchaud, V., Toba, S., and Greenbaum, D. (2000). Selective targeting of lysosomal cysteine proteases with radiolabeled electrophilic substrate analogs. Chem. Biol. 7, 27-38.

BoseDasgupta, S., Das, B. B., Sengupta, S., Ganguly, A., Roy, A., Dey, S., Tripathi, G., Dinda, B., and caspase-independent algorithm of programmed cell death in Leishmania induced by baicalein: the role of LdEndoG, LdFEN-1 and LdTatD as a DNA 'degradesome'. Cell Death Differ. 15, 1629-1640.

Bournazou, I., Pound, J. D., Duffin, R., Bournazos, S., Melville, L. A., Brown, S. B., Rossi, A. G., and Gregory, C. D. (2009). Apoptotic Majumder, H. K. (2008). The

to the intrinsic apoptosis pathway of mammalian cells. Although experimental observations are limited, there is increasing evidence to support the idea that protozoan parasites use PCD for controlling their population in the infected host. Possibly, Leishmania could use PCD either in the insect vector to favor the survival of infectious metacyclic forms, or in the mammalian host to avoid hyperparasitism that would prematurely kill the host. In addition, recent evidences suggest that Leishmania also exploits features of PCD to facilitate its silent entry in the mammalian host and establish a successful infection. However, there is much work ahead to decipher the multiple roles played by PCD in the biology of Leishmania.

\section{ACKNOWLEDGMENTS}

We thank Dr. Hira Nakhasi for his critical reading of the manuscript.

human cells inhibit migration of granulocytes via release of lactoferrin. J. Clin. Invest. 119, 20-32.

Brenner, D., and Mak, T. W. (2009) Mitochondrial cell death effectors. Curr. Opin. Cell Biol. 21, 871-877.

Ch'ng, J. H., Kotturi, S. R., Chong, A G., Lear, M. J., and Tan, K. S. (2010) A programmed cell death pathway in the malaria parasite Plasmodium falciparum has general features of mammalian apoptosis but is mediated by clan CA cysteine proteases. Cell Death Dis. 1, e26.

Chose, O., Noel, C., Gerbod, D. Brenner, C., Viscogliosi, E., and Roseto, A. (2002). A form of cell death with some features resembling apoptosis in the amitochondrial unicellular organism Trichomonas vaginalis. Exp. Cell Res. 276, 32-39.

Cohen, M. S., Zhang, C., Shokat, K. M., and Taunton, J. (2005). Structural bioinformatics-based design of selective, irreversible kinase inhibitors. Science 308, 1318-1321.

Coll, N. S., Vercammen, D., Smidler, A., Clover, C., Van Breusegem, F., Dangl, J. L., and Epple, P. (2010). Arabidopsis type I metacaspases control cell death. Science 330, 1393-1397.

David, K. K., Sasaki, M., Yu, S. W. Dawson, T. M., and Dawson, V. L. (2006). EndoG is dispensable in embryogenesis and apoptosis. Cell Death Differ. 13, 1147-1155.

Debnath, J., Baehrecke, E. H. and Kroemer, G. (2005). Does autophagy contribute to cell death? Autophagy 1, 66-74.

Debrabant, A., Lee, N., Bertholet, S., Duncan, R., and Nakhasi, H. L. (2003). Programmed cell death in trypanosomatids and other unicellular organisms. Int. J. Parasitol. 33, 257-267.

Debrabant, A., Lee, N., Pogue, G. P. Dwyer, D. M., and Nakhasi, H. L. (2002). Expression of calreticulin P-domain results in impairment of secretory pathway in Leishmania donovani and reduced parasite survival in macrophages. Int. J. Parasitol. 32, 1423-1434.

de Freitas Balanco, J. M., Moreira, M. E., Bonomo, A., Bozza, P. T., Amarante-Mendes, G., Pirmez, C., and Barcinski, M. A. (2001) Apoptotic mimicry by an obligate intracellular parasite downregulates macrophage microbicidal activity. Curr. Biol. 11, 1870-1873.

Deponte, M., and Becker, K. (2004). Plasmodium falciparum-do killers commit suicide? Trends Parasitol. 20, 165-169.

Duszenko, M., Figarella, K., Macleod, E. T., and Welburn, S. C. (2006). Death of a trypanosome: a selfish altruism. Trends Parasitol. 22, 536-542.

Ekert, P. G., Read, S. H., Silke, J., Marsden, V. S., Kaufmann, H., Hawkins, C. J., Gerl, R., Kumar, S., and Vaux, D. L. (2004). Apaf-1 and caspase- 9 accelerate apoptosis, but do not determine whether factordeprived or drug-treated cells die. J. Cell Biol. 165, 835-842.

Esseiva, A. C., Chanez, A. L., BochudAllemann, N., Martinou, J. C., Hemphill, A., and Schneider, A. (2004). Temporal dissection of Baxinduced events leading to fission of the single mitochondrion in Trypanosoma brucei. EMBO Rep. 5, 268-273.

Figarella, K., Rawer, M., Uzcategui, N. L., Kubata, B. K., Lauber, K., Madeo, F., Wesselborg, S., and 
Duszenko, M. (2005). Prostaglandin D2 induces programmed cell death in Trypanosoma brucei bloodstream form. Cell Death Differ. 12, 335-346.

França-Costa, J., Wanderley, J. L., Deolindo, P., Zarattini, J. B., Costa, J., Soong, L., Barcinski, M. A., Barral, A., and Borges, V. M. (2012). Exposure of phosphatidylserine on Leishmania amazonensis isolates is associated with diffuse cutaneous leishmaniasis and parasite infectivity. PLoS ONE 7:e36595. doi: 10.1371/journal.pone.0036595

Fuertes, M. A., Nguewa, P. A., Castilla, J., Alonso, C., and Perez, J. M. (2008). Anticancer compounds as leishmanicidal drugs: challenges in chemotherapy and future perspectives. Curr. Med. Chem. 15, 433-439.

Galluzzi, L., Vitale, I., Abrams, J. M., Alnemri, E. S., Baehrecke, E. H., Blagosklonny, M. V., Dawson, T. M., Dawson, V. L., El-Deiry, W. S., Fulda, S., Gottlieb, E., Green, D. R., Hengartner, M. O., Kepp, O., Knight, R. A., Kumar, S., Lipton, S. A., Lu, X., Madeo, F., Malorni, W., Mehlen, P., Nunez, G., Peter, M. E., Piacentini, M., Rubinsztein, D. C., Shi, Y., Simon, H. U., Vandenabeele, P., White, E., Yuan, J., Zhivotovsky, B., Melino, G., and Kroemer, G. (2012). Molecular definitions of cell death subroutines: recommendations of the Nomenclature Committee on Cell Death 2012. Cell Death Differ. 19, 107-120.

Gannavaram, S., and Debrabant, A. (2012). Involvement of TatD nuclease during programmed cell death in the protozoan parasite Trypanosoma brucei. Mol. Microbiol. $83,926-935$.

Gannavaram, S., Vedvyas, C., and Debrabant, A. (2008). Conservation of the pro-apoptotic nuclease activity of endonuclease $\mathrm{G}$ in unicellular trypanosomatid parasites. J. Cell Sci. 121, 99-109.

Ghosh, E., Ghosh, A., Ghosh, A. N., Nozaki, T., and Ganguly, S. (2009). Oxidative stress-induced cell cycle blockage and a proteaseindependent programmed cell death in microaerophilic Giardia lamblia. Drug Des. Dev. Ther. 3, 103-110.

Gonzalez, I. J., Desponds, C., Schaff, C., Mottram, J. C., and Fasel, N. (2007). Leishmania major metacaspase can replace yeast metacaspase in programmed cell death and has arginine-specific cysteine peptidase activity. Int. J. Parasitol. 37, 161-172.

Gossage, S. M., Rogers, M. E., and Bates, P. A. (2003). Two separate growth phases during the development of Leishmania in sand flies: implications for understanding the life cycle. Int. J. Parasitol. 33, 1027-1034.

Green, D. R., and Reed, J. C. (1998) Mitochondria and apoptosis. Science 281, 1309-1312.

Handman, E. (1999). Cell biology of Leishmania. Adv. Parasitol. 44, 1-39.

Hao, Z., Duncan, G. S., Chang, C. C., Elia, A., Fang, M., Wakeham, A., Okada, H., Calzascia, T., Jang, Y., You-Ten, A., Yeh, W. C., Ohashi, P., Wang, X., and Mak, T. W. (2005). Specific ablation of the apoptotic functions of cytochrome $C$ reveals a differential requirement for cytochrome C and Apaf- 1 in apoptosis. Cell 121, 579-591.

Huttemann, M., Pecina, P., Rainbolt, M., Sanderson, T. H., Kagan, V. E. Samavati, L., Doan, J. W., and Lee, I. (2011). The multiple functions of cytochrome $\mathrm{c}$ and their regulation in life and death decisions of the mammalian cell: from respiration to apoptosis. Mitochondrion 11, 369-381.

Huynh, M. L., Fadok, V. A., and Henson, P. M. (2002). Phosphatidylserine-dependent ingestion of apoptotic cells promotes TGF-betal secretion and the resolution of inflammation. J. Clin. Invest. 109, 41-50.

Ivanovska, I., and Hardwick, J. M. (2005). Viruses activate a genetically conserved cell death pathway in a unicellular organism. J. Cell Biol. 170, 391-399.

Ives, A., Ronet, C., Prevel, F., Ruzzante, G., Fuertes-Marraco, S., Schutz, F., Zangger, H., Revaz-Breton, M., Lye, L. F., Hickerson, S. M., Beverley, S. M., Acha-Orbea, H., Launois, P., Fasel, N., and Masina, S. (2011). Leishmania RNA virus controls the severity of mucocutaneous leishmaniasis. Science 331, 775-778.

Jimenez-Ruiz, A., Alzate, J. F., Macleod, E. T., Luder, C. G., Fasel, N., and Hurd, H. (2010). Apoptotic markers in protozoan parasites. Parasit. Vectors 3, 104

Klionsky, D. J., Abeliovich, H., Agostinis, P., Agrawal, D. K., Aliev, G., Askew, D. S., Baba, M., Baehrecke, E. H., Bahr, B. A., Ballabio, A., Bamber, B. A., Bassham, D. C., Bergamini, E., Bi, X., Biard-Piechaczyk, M., Blum, J. S., Bredesen, D. E., Brodsky, J. L., Brumell, J. H., Brunk, U. T., Bursch, W., Camougrand, N., Cebollero, E., Cecconi, F., Chen, Y., Chin, L. S., Choi, A., Chu, C. T., Chung, J., Clarke, P. G., Clark, R. S., Clarke, S. G., Clave, C., Cleveland, J. L., Codogno, P., Colombo, M. I., Coto-Montes, A., Cregg, J.
M., Cuervo, A. M., Debnath, J., Demarchi, F., Dennis, P. B., Dennis, P. A., Deretic, V., Devenish, R. J., Di Sano, F., Dice, J. F., Difiglia, M., Dinesh-Kumar, S., Distelhorst, C. W., Djavaheri-Mergny, M., Dorsey, F. C., Droge, W., Dron, M., Dunn, W. A. Jr., Duszenko, M., Eissa, N. T., Elazar, Z., Esclatine, A., Eskelinen, E. L., Fesus, L., Finley, K. D., Fuentes, J. M., Fueyo, J., Fujisaki, K., Galliot, B., Gao, F. B., Gewirtz, D. A., Gibson, S. B., Gohla, A., Goldberg, A. L., Gonzalez, R., Gonzalez-Estevez, C., Gorski, S., Gottlieb, R. A., Haussinger, D. He, Y. W., Heidenreich, K., Hill, J. A., Hoyer-Hansen, M., Hu, X., Huang, W. P., Iwasaki, A., Jaattela, M., Jackson, W. T., Jiang, X., Jin, S., Johansen, T., Jung, J. U., Kadowaki, M., Kang, C., Kelekar, A., Kessel, D. H., Kiel, J. A., Kim, H. P., Kimchi, A., Kinsella, T. J., Kiselyov, K., Kitamoto, K., Knecht, E., Komatsu, M., Kominami, E., Kondo, S., Kovacs, A. L., Kroemer, G., Kuan, C. Y., Kumar, R., Kundu, M., Landry, J., Laporte, M., Le, W., Lei, H. Y., Lenardo, M. J., Levine, B., Lieberman, A., Lim, K. L., Lin, F. C., Liou, W., Liu, L. F., Lopez-Berestein, G., Lopez-Otin, C., Lu, B., Macleod, K. F., Malorni, W., Martinet, W., Matsuoka, K., Mautner, J., Meijer, A. J., Melendez, A., Michels, P., Miotto, G., Mistiaen, W. P., Mizushima, N., Mograbi, B., Monastyrska, I., Moore, M. N. Moreira, P. I., Moriyasu, Y., Motyl, T., Munz, C., Murphy, L. O., Naqvi, N. I., Neufeld, T. P., Nishino, I., Nixon, R. A., Noda, T., Nurnberg, B., Ogawa, M., Oleinick, N. L., Olsen, L. J., Ozpolat, B., Paglin, S., Palmer, G. E., Papassideri, I., Parkes, M., Perlmutter, D. H., Perry, G., Piacentini, M., Pinkas-Kramarski, R., Prescott, M., Proikas-Cezanne, T., Raben, N., Rami, A., Reggiori, F., Rohrer, B., Rubinsztein, D. C., Ryan, K. M., Sadoshima, J., Sakagami, H., Sakai, Y., Sandri, M., Sasakawa, C., Sass, M., Schneider, C., Seglen, P. O., Seleverstov, O. Settleman, J., Shacka, J. J., Shapiro, I. M., Sibirny, A., Silva-Zacarin, E. C., Simon, H. U., Simone, C., Simonsen, A., Smith, M. A., SpanelBorowski, K., Srinivas, V., Steeves, M., Stenmark, H., Stromhaug, P. E., Subauste, C. S., Sugimoto, S., Sulzer, D., Suzuki, T., Swanson, M. S., Tabas, I., Takeshita, F., Talbot, N. J., Talloczy, Z., Tanaka, K., Tanida, I., Taylor, G. S., Taylor, J. P., Terman, A., Tettamanti, G., Thompson, C. B., Thumm, M., Tolkovsky, A. M., Tooze, S. A.,
Truant, R., Tumanovska, L. V., Uchiyama, Y., Ueno, T., Uzcategui, N. L., van der Klei, I., Vaquero, E. C., Vellai, T., Vogel, M. W., Wang, H. G., Webster, P., Wiley, J. W., Xi, Z., Xiao, G., Yahalom, J., Yang, J. M., Yap, G., Yin, X. M., Yoshimori, T., Yu, L., Yue, Z., Yuzaki, M., Zabirnyk, O., Zheng, X., Zhu, X., and Deter, R. L. (2008). Guidelines for the use and interpretation of assays for monitoring autophagy in higher eukaryotes. Autophagy 4, 151-175.

Kroemer, G., Galluzzi, L. Vandenabeele, P., Abrams, J., Alnemri, E. S., Baehrecke, E. H., Blagosklonny, M. V., El-Deiry, W. S., Golstein, P., Green, D. R., Hengartner, M., Knight, R. A., Kumar, S., Lipton, S. A., Malorni, W., Nunez, G., Peter, M. E. Tschopp, J., Yuan, J., Piacentini, M., Zhivotovsky, B., and Melino, G. (2009). Classification of cell death: recommendations of the Nomenclature Committee on Cell Death (2009). Cell Death Differ. 16, 3-11.

Kumar, S., Zhou, B., Liang, F., Wang, W. Q., Huang, Z., and Zhang, Z. Y. (2004). Activity-based probes for protein tyrosine phosphatases. Proc. Natl. Acad. Sci. U.S.A. 101, 7943-7948.

Lee, N., Bertholet, S., Debrabant, A., Muller, J., Duncan, R., and Nakhasi, H. L. (2002). Programmed cell death in the unicellular protozoan parasite Leishmania. Cell Death Differ. 9, 53-64.

Lee, N., Gannavaram, S., Selvapandiyan, A., and Debrabant, A. (2007). Characterization of metacaspases with trypsin-like activity and their putative role in programmed cell death in the protozoan parasite Leishmania. Eukaryot. Cell 6, 1745-1757.

Li, L. Y., Luo, X., and Wang, X. (2001). Endonuclease $\mathrm{G}$ is an apoptotic DNase when released from mitochondria. Nature 412, 95-99.

Li, W. (2012). Eat-me signals: keys to molecular phagocyte biology and "appetite" control. J. Cell Physiol. 227, 1291-1297.

Luder, C. G., Campos-Salinas, J., Gonzalez-Rey, E., and van Zandbergen, G. (2010). Impact of protozoan cell death on parasitehost interactions and pathogenesis. Parasit. Vectors 3, 116.

Ludovico, P., Rodrigues, F., Almeida, A., Silva, M. T., Barrientos, A., and Corte-Real, M. (2002). Cytochrome c release and mitochondria involvement in programmed cell death induced by acetic acid in 
Saccharomyces cerevisiae. Mol. Biol. Cell 13, 2598-2606.

Lye, L. F., Owens, K., Shi, H., Murta, S. M., Vieira, A. C., Turco, S. J., Tschudi, C., Ullu, E., and Beverley, S. M. (2010). Retention and loss of RNA interference pathways in trypanosomatid protozoans. PLoS Pathog. 6:e1001161. doi: 10.1371/journal.ppat.1001161

Martin, S. J., Reutelingsperger, C. P., McGahon, A. J., Rader, J. A., van Schie, R. C., LaFace, D. M., and Green, D. R. (1995). Early redistribution of plasma membrane phosphatidylserine is a general feature of apoptosis regardless of the initiating stimulus: inhibition by overexpression of Bcl-2 and Abl. J. Exp. Med. 182, 1545-1556.

Martins, I., Kepp, O., Galluzzi, L., Senovilla, L., Schlemmer, F., Adjemian, S., Menger, L., Michaud, M., Zitvogel, L., and Kroemer, G. (2010). Surface-exposed calreticulin in the interaction between dying cells and phagocytes. Ann. N.Y. Acad. Sci. 1209, 77-82.

McDermott-Roe, C., Ye, J., Ahmed, R., Sun, X. M., Serafin, A., Ware, J., Bottolo, L., Muckett, P., Canas, X., Zhang, J., Rowe, G. C., Buchan, R., Lu, H., Braithwaite, A., Mancini, M., Hauton, D., Marti, R., GarciaArumi, E., Hubner, N., Jacob, H., Serikawa, T., Zidek, V., Papousek, F., Kolar, F., Cardona, M., RuizMeana, M., Garcia-Dorado, D., Comella, J. X., Felkin, L. E., Barton, P. J., Arany, Z., Pravenec, M., Petretto, E., Sanchis, D., and Cook, S. A. (2011). Endonuclease $\mathrm{G}$ is a novel determinant of cardiac hypertrophy and mitochondrial function. Nature 478, 114-118.

Mercer, J., and Helenius, A. (2008). Vaccinia virus uses macropinocytosis and apoptotic mimicry to enter host cells. Science 320, 531-535.

Meslin, B., Barnadas, C., Boni, V., Latour, C., De Monbrison, F., Kaiser, K., and Picot, S. (2007). Features of apoptosis in Plasmodium falciparum erythrocytic stage through a putative role of PfMCA1 metacaspaselike protein. J. Infect. Dis. 195, 1852-1859.

Meslin, B., Beavogui, A. H., Fasel, N., and Picot, S. (2011). Plasmodium falciparum metacaspase PfMCA-1 triggers a z-VAD-fmk inhibitable protease to promote cell death. PLoS ONE 6:e23867. doi: 10.1371/journal.pone. 0023867

Mukherjee, S. B., Das, M., Sudhandiran, G., and Shaha, C.
(2002). Increase in cytosolic Ca2+ levels through the activation of nonselective cation channels induced by oxidative stress causes mitochondrial depolarization leading to apoptosis-like death in Leishmania donovani promastigotes. J. Biol. Chem. 277, 24717-24727.

Nakagawa, A., Shi, Y., Kage-Nakadai, E., Mitani, S., and Xue, D. (2010). Caspase-dependent conversion of Dicer ribonuclease into a deathpromoting deoxyribonuclease. Science 328, 327-334.

Obeid, M., Tesniere, A., Ghiringhelli, F., Fimia, G. M., Apetoh, L., Perfettini, J. L., Castedo, M., Mignot, G., Panaretakis, T., Casares, N., Metivier, D., Larochette, N., van Endert, P., Ciccosanti, F., Piacentini, M., Zitvogel, L., and Kroemer, G. (2007). Calreticulin exposure dictates the immunogenicity of cancer cell death. Nat. Med. 13, 54-61.

Ogden, C. A., deCathelineau, A., Hoffmann, P. R., Bratton, D., Ghebrehiwet, B., Fadok, V. A., and Henson, P. M. (2001). C1q and mannose binding lectin engagement of cell surface calreticulin and CD91 initiates macropinocytosis and uptake of apoptotic cells. J. Exp. Med. 194, 781-795.

Paris, C., Loiseau, P. M., Bories, C., and Breard, J. (2004). Miltefosine induces apoptosis-like death in Leishmania donovani promastigotes. Antimicrob. Agents Chemother. $48,852-859$.

Parrish, J., Li, L., Klotz, K., Ledwich, D., Wang, X., and Xue, D. (2001) Mitochondrial endonuclease $G$ is important for apoptosis in C. elegans. Nature 412, 90-94.

Parrish, J. Z., and Xue, D. (2003). Functional genomic analysis of apoptotic DNA degradation in C. elegans. Mol. Cell 11, 987-996.

Peng, B. W., Lin, J., Lin, J. Y., Jiang, M. S., and Zhang, T. (2003). Exogenous nitric oxide induces apoptosis in Toxoplasma gondii tachyzoites via a calcium signal transduction pathway. Parasitology 126, 541-550.

Peters, N. C., Egen, J. G., Secundino, N., Debrabant, A., Kimblin, N. Kamhawi, S., Lawyer, P., Fay, M. P., Germain, R. N., and Sacks, D. (2008). In vivo imaging reveals an essential role for neutrophils in leishmaniasis transmitted by sand flies. Science 321, 970-974.

Pradelli, L. A., Beneteau, M., and Ricci, J. E. (2010). Mitochondrial control of caspase-dependent and independent cell death. Cell. Mol. Life Sci. 67, 1589-1597.
Rico, E., Alzate, J. F., Arias, A. A., Moreno, D., Clos, J., Gago, F. Moreno, I., Dominguez, M. and Jimenez-Ruiz, A. (2009). Leishmania infantum expresses a mitochondrial nuclease homologous to EndoG that migrates to the nucleus in response to an apoptotic stimulus. Mol. Biochem. Parasitol. 163, 28-38.

Ronet, C., Beverley, S. M., and Fasel, N. (2011). Muco-cutaneous leishmaniasis in the New World: the ultimate subversion. Virulence 2, 547-552.

Schmitt, M. J., and Reiter, J. (2008) Viral induced yeast apoptosis. Biochim. Biophys. Acta 1783, 1413-1417.

Sen, N., Das, B. B., Ganguly, A., Mukherjee, T., Bandyopadhyay, S., and Majumder, H. K. (2004) Camptothecin-induced imbalance in intracellular cation homeostasis regulates programmed cell death in unicellular hemoflagellate Leishmania donovani. J. Biol. Chem. 279, 52366-52375.

Sereno, D., Holzmuller, P., Mangot, I., Cuny, G., Ouaissi, A., and Lemesre, J. L. (2001). Antimonialmediated DNA fragmentation in Leishmania infantum amastigotes. Antimicrob. Agents Chemother. 45, 2064-2069.

Shi, H., Tschudi, C., and Ullu, E. (2006). An unusual Dicer-likel protein fuels the RNA interference pathway in Trypanosoma brucei RNA 12, 2063-2072.

Silva, R. D., Sotoca, R., Johansson, B. Ludovico, P., Sansonetty, F., Silva, M. T., Peinado, J. M., and CorteReal, M. (2005). Hyperosmotic stress induces metacaspase- and mitochondria-dependent apoptosis in Saccharomyces cerevisiae. Mol. Microbiol. 58, 824-834.

Singh, G., Jayanarayan, K. G., and Dey, C. S. (2005). Novobiocin induces apoptosis-like cell death in topoisomerase II over-expressing arsenite resistant Leishmania donovani. Mol. Biochem. Parasitol. 141, 57-69.

Smirlis, D., Duszenko, M., Ruiz, A J., Scoulica, E., Bastien, P., Fasel, N., and Soteriadou, K. (2010). Targeting essential pathways in trypanosomatids gives insights into protozoan mechanisms of cell death. Parasit. Vectors 3, 107.

Tang, X., Halleck, M. S., Schlegel, R. A., and Williamson, P. (1996) A subfamily of P-type ATPases with aminophospholipid transporting activity. Science 272, 1495-1497.

Uren, A. G., O'Rourke, K., Aravind L. A., Pisabarro, M. T., Seshagiri, S., Koonin, E. V., and Dixit, V.
M. (2000). Identification of paracaspases and metacaspases: two ancient families of caspase-like proteins, one of which plays a key role in MALT lymphoma. Mol. Cell 6, 961-967.

van Zandbergen, G., Bollinger, A. Wenzel, A., Kamhawi, S., Voll, R., Klinger, M., Muller, A., Holscher, C., Herrmann, M., Sacks, D., Solbach, W., and Laskay, T. (2006). Leishmania disease development depends on the presence of apoptotic promastigotes in the virulent inoculum. Proc. Natl. Acad. Sci. U.S.A. 103, 13837-13842.

van Zandbergen, G., Klinger, M., Mueller, A., Dannenberg, S., Gebert, A., Solbach, W., and Laskay, T. (2004). Cutting edge: neutrophil granulocyte serves as a vector for Leishmania entry into macrophages. J. Immunol. 173, 6521-6525.

van Zandbergen, G., Luder, C. G., Heussler, V., and Duszenko, M. (2010). Programmed cell death in unicellular parasites: a prerequisite for sustained infection? Trends Parasitol. 26, 477-483.

van Zandbergen, G., Solbach, W., and Laskay, T. (2007). Apoptosis driven infection. Autoimmunity 40, 349-352.

Vandivier, R. W., Ogden, C. A., Fadok, V. A., Hoffmann, P. R., Brown, K. K., Botto, M., Walport, M. J., Fisher, J. H., Henson, P. M., and Greene, K. E. (2002). Role of surfactant proteins $\mathrm{A}, \mathrm{D}$, and $\mathrm{Clq}$ in the clearance of apoptotic cells in vivo and in vitro: calreticulin and CD91 as a common collectin receptor complex. J. Immunol. 169, 3978-3986.

Vassella, E., Reuner, B., Yutzy, B., and Boshart, M. (1997). Differentiation of African trypanosomes is controlled by a density sensing mechanism which signals cell cycle arrest via the cAMP pathway. J. Cell Sci. 110(Pt 21), 2661-2671.

Villalba, J. D., Gomez, C., Medel, O., Sanchez, V., Carrero, J. C. Shibayama, M., and Ishiwara, D. G. (2007). Programmed cell death in Entamoeba histolytica induced by the aminoglycoside G418. Microbiology 153, 3852-3863.

Wanderley, J. L., Moreira, M. E., Benjamin, A., Bonomo, A. C., and Barcinski, M. A. (2006). Mimicry of apoptotic cells by exposing phosphatidylserine participates in the establishment of amastigotes of Leishmania ( $L$ ) amazonensis in mammalian hosts. J. Immunol. 176, $1834-1839$

Wang, X., Yang, C., Chai, J., Shi, Y., and Xue, D. (2002). Mechanisms 
of AIF-mediated apoptotic DNA degradation in Caenorhabditis elegans. Science 298, 1587-1592.

Welburn, S. C., and Maudlin, I. (1997). Control of Trypanosoma brucei brucei infections in tsetse, Glossina morsitans. Med. Vet. Entomol. 11, 286-289.

Zalila, H., Gonzalez, I. J., El-Fadili, A. K., Delgado, M. B., Desponds, C., Schaff, C., and Fasel, N. (2011). Processing of metacaspase into a cytoplasmic catalytic domain mediating cell death in Leishmania major. Mol. Microbiol. 79, 222-239.

Zangger, H., Mottram, J. C., and Fasel, N. (2002). Cell death in Leishmania induced by stress and differentiation: programmed cell death or necrosis? Cell Death Differ. 9, 1126-1139.

Conflict of Interest Statement: The authors declare that the research was conducted in the absence of any commercial or financial relationships that could be construed as a potential conflict of interest.

Received: 15 March 2012; paper pending published: 18 April 2012; accepted: 21 June 2012; published online: 10 July 2012.

Citation: Gannavaram S and Debrabant A (2012) Programmed cell death in Leishmania: biochemical evidence and role in parasite infectivity. Front. Cell. Inf. Microbio. 2:95. doi: 10.3389/fcimb. 2012.00095

Copyright (c) 2012 Gannavaram and Debrabant. This is an open-access article distributed under the terms of the Creative Commons Attribution License, which permits use, distribution and reproduction in other forums, provided the original authors and source are credited and subject to any copyright notices concerning any third-party graphics etc. 